Journal of Natural History, 1987, 21, 1097-1107

\title{
New trophobiotic symbioses of ants with South East Asian Bugs
}

\author{
U. MASCHWITZ, B. FIALA and W. R. DOLLING $\dagger$ \\ Fachbereich Biologie, Zoologie, der Universität, 6000 Frankfurt am Main, \\ Siesmayerstrasse 70, FR Germany, and †British Museum (Natural \\ History), Department of Entomology, Cromwell Road, London $S W 75 B D$, \\ $U K$
}

(Accepted 28 January 1987)

\begin{abstract}
A trophobiotic relationship between two species of phloem-feeding plataspid bugs and an ant, Meranoplus mucronatus, was discovered on tree trunks in Malaysia. Similar relationships were found between coreid bugs and Crematogaster $\mathrm{sp}$. and Anoplolepis longipes, on bamboo in the same area. The ants recruit to groups of the bugs and feed on the liquid, sugar-rich faeces of the larvae, stimulating release of the honeydew by tactile signals. They protect all stages of the bugs from disturbance by biting and by the use of defensive secretions. Phloem-feeding bugs in the families Plataspidae and Coreidae need long stylets to pierce the thick bark of their host tree. The different methods of accommodating the resting stylets in these two families are described. The plataspids are described as Tropidotylus servus sp. nov. and $T$. minister sp. nov. A coreid previously reported in association with $M$. mucronatus in Malaya is described as Hygia cliens sp. nov. The coreids on bamboo were determined as Cloresmus spp. and Notobitus affinis.
\end{abstract}

KeYwords: Ants, Coreidae, Heteroptera, Malaya, New Species, Plataspidae, Trophobiosis.

\section{Introduction}

Trophobiotic relationships of ants with Sternorrhyncha and Auchenorrhyncha are widespread but few such relationships have been reported between ants and phytophagous Heteroptera. We have been able to trace only two reports in which such relationships have been definitely stated to be trophobiotic. These reports involve a species of Plataspidae in Sri Lanka (Green, 1900) and a species of Coreidae in Malaya (Maschwitz and Klinger, 1974).

Maschwitz and Klinger (1974) described an association of ants with a Malayan coreid, Colpura sp., which is the species described below as Hygia cliens. Behavioural and morphological observations led them to postulate that this bug was a phloemfeeder living in a trophobiotic association with ants. Since then, Maschwitz and Fiala have repeatedly observed this relationship and are able to confirm that it involves a true trophobiosis. Additionally, Heteroptera of two other genera were found to live in the same kind of association with ants and these new findings form the basis of this paper. We think it likely that ant-heteropteran trophobiosis is more widespread than the published records suggest. It is known that some Aradidae, which have long stylets but a short rostrum, feed from phloem, and many Miridae have similar feeding habits. It seems probable that some species of both of these families, as well as other Coreidae and Pentatomoidea, will be found living trophobiotically with ants as the biology of tropical Heteroptera becomes better known. 
Biology (U. Maschwitz and B. Fiala)

\section{Materials and methods}

The observations were carried out in the vicinity of the Gombak Field Station of the University of Malaya. This station is situated in the western coastal mountains near Kuala Lumpur. The ant/bug associations were found in mid-January 1986 in a secondary forest: one on the trunk of a broad-leafed tree, the other on bamboo shoots. To determine the sugar content in the bugs' excreta, we used Dextrostix/Merck (blood sugar test sticks) yielding maximum coloration at $250 \mathrm{mg}$ glucose $/ 100 \mathrm{ml}$.

\section{Results}

The Tropidotylus/Meranoplus mucronatus association. This association was found near the field station on the trunk of an unidentified broad-leafed tree. It persisted throughout the 4-week observation period. In the associations two species of Tropidotylus were found, mainly $T$. servus sp. nov., with a few $T$. minister sp. nov.

The bugs were stationed on the lower part of the trunk, between the root area and a height of $1.5 \mathrm{~m}$. The trunk had a diameter of $60 \mathrm{~cm}$. Some of the bugs were located in 10 pavilions, $6-27 \mathrm{~cm}$ long by $2-4 \mathrm{~cm}$ wide, that were built around a vine. The other bugs were sitting at 14 sites without pavilions, in the narrow spaces between the vines and the trunk near the roots.

The pavilions were constructed of small pieces of wood, moss and bark. Their floors had been cleared of such detritus by the ants. They housed groups of up to 20 bugs whereas outside of them only solitary bugs or very small groups were seen.

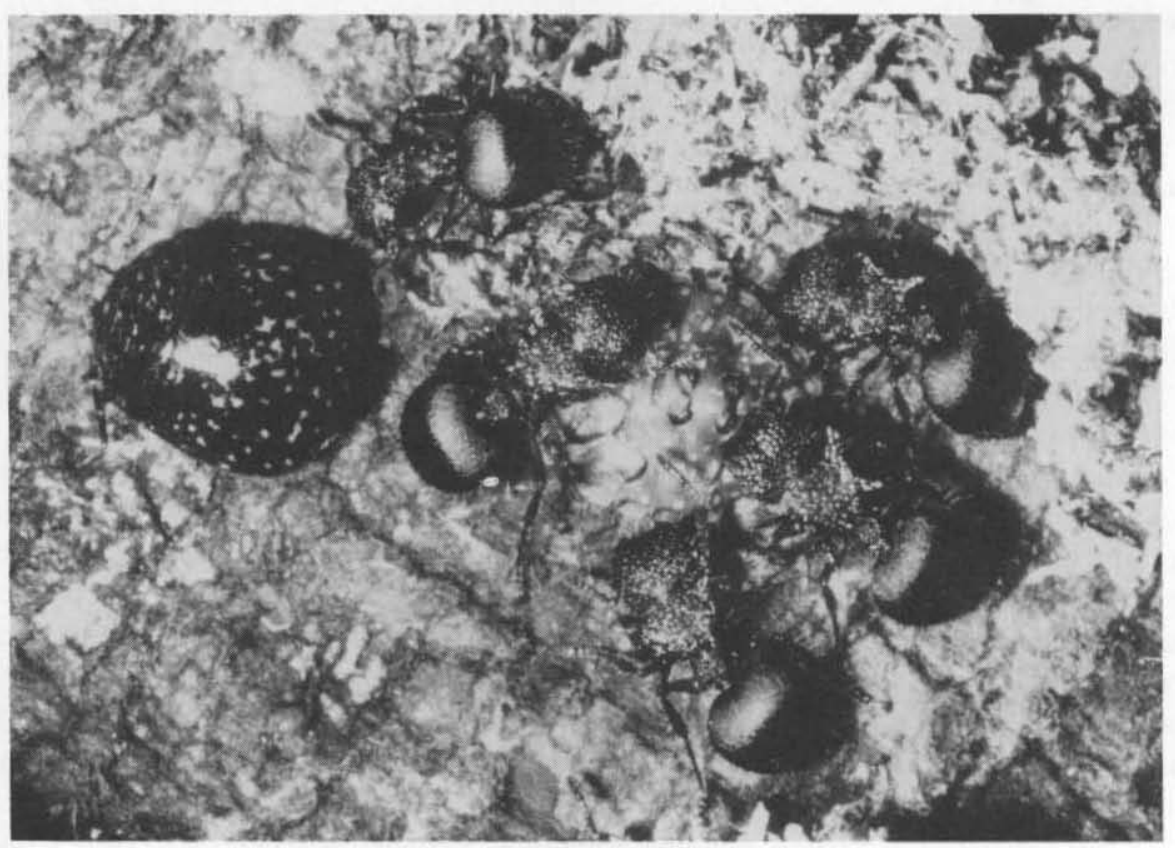

FIG. 1. Trophobiotic association of Tropidotylus servus and Meranoplus mucronatus on the bark of a broad-leafed tree. The workers are attracted much more to the well camouflaged larva (centre) than to the adult (left). 
Each pavilion contained three to eight adults and 10-25 larvae of various ages, as well as a total of eight clutches of four to ten eggs. In all there were 150-200 bugs attended by approximately three times as many ants at any one time. Larvae and adult bugs were mixed irregularly. The larvae were mostly oriented head upwards, probably to avoid contamination by their own excreta. The adults showed no preferred orientation. Due to their flat bodies and brown and green coloration the larvae were extremely well camouflaged. When pressed tightly against the tree trunk they resembled lichen-covered pieces of bark (Fig. 1).

When we opened a pavilion the larvae would remain motionless for a long time except for some movements of the antennae. Only hours later would they start to walk to other places of concealment, often near to other bugs. The adults were much more prone to move when disturbed and quickly settled again close to other bugs. Ants crawling over them and and touching them with their antennae did not disturb the bugs at all. When we caught the bugs with our hands, however, they released a strongsmelling defensive secretion. They did not drop to the ground as many other bugs do when disturbed. Workers of Meranoplus mucronatus were clustered around each bug. Larvae of all stages were surrounded by up to six ants, which preferentially palpated the bugs' anal regions with their antennae. Adult bugs received much less attention. The larvae continuously defecated. Glucose tests on these excretions were positive and three times indicated the maximum concentration detectable by this method. No special behaviour was noted in connection with excretion. Larvae excreted droplets of up to $1 \mathrm{~mm}$ diameter. The intervals between production of droplets by three large larvae were, respectively, 4, 4, 4, 7 and $7 \mathrm{~min} ; 4,7,12,22$ and $30 \mathrm{~min}$; and $1 \mathrm{~min}$ and $50 \mathrm{~s}$. Droplets were usually produced immediately after the bugs had been touched by an ant's antennae and the fluid was immediately imbibed by the ants. Only when larvae were isolated from contact with ants did they excrete spontaneously, the excreta then dropping to the ground. During $3 \mathrm{~h}$ of observation we did not observe any excretion by adult bugs and it remained unclear if they were feeding at all.

Ants were always present in large numbers near the bugs and had laid a trail to them. While they showed no aggression towards the bugs, the ants immediately attacked foreign objects, such as forceps, brought near them by the observers. It was difficult to chase the ants away from the bugs. They bit the forceps and pressed their erected gasters with sideways motions against them, simultaneously secreting a defensive fluid from the extended, reduced sting.

On the same tree trunk at the same height we also found Meranoplus mucronatus associated with a small number of Hygia cliens. The latter also excreted a fluid containing glucose and the ants defended them in the same way as they defended Tropidotylus.

The Cloresmus/Crematogaster association. On small auxiliary shoots, about $1 \mathrm{~m}$ long, of a bamboo, Gigantochloa scortechini, we discovered small groups of a coreid bug, Cloresmus sp. The groups consisted of adults and larvae of various stages and were visited by ants, Crematogaster $\mathrm{sp}$. These associations persisted over a period of more than 2 months. The bugs were always located at the nodal regions of the shoots. We had noted similar associations of Cloresmus with Meranoplus mucronatus on Gigantochloa in previous years.

Cloresmus larvae that had not been attended by ants for some time were noticed with large droplets emerging from the anus (Fig. 2). In the absence of ants the larvae eventually turned slightly away from the stem, with the abdomen extended, until the droplets fell away. The droplets were produced at intervals of 4-15 min (average 7 


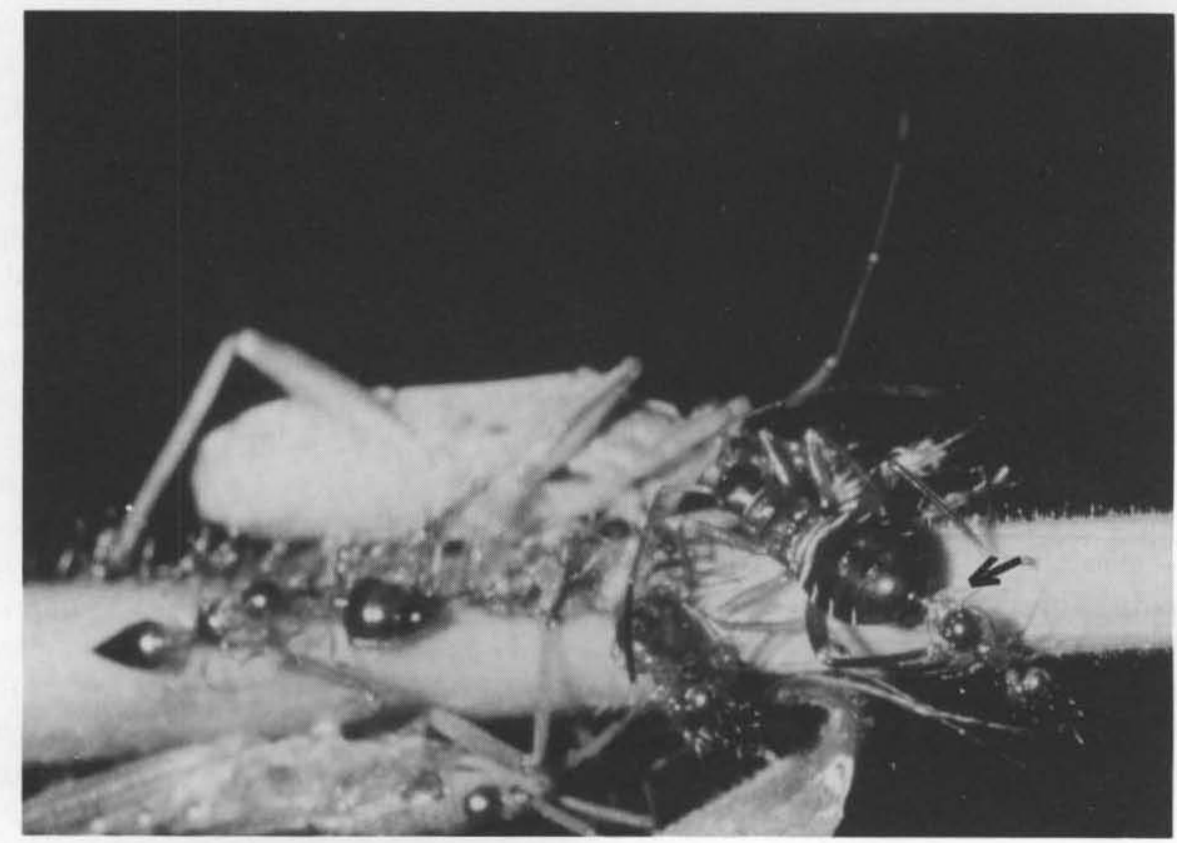

FIG. 2. Trophobiotic association of Cloresmus sp. and Crematogaster sp. on bamboo. The larva releases from its abdominal apex a droplet of honeydew, which is consumed by an ant.

min). They contained the maximum glucose concentration that could be measured by the Dextrostix test. Most of the time the Cloresmus larvae were surrounded by Crematogaster workers. At our main observation shoot, usually two to three larvae of various ages and one or two adults were attended by an average of nine workers. The larvae were attractive to the ants, which frequently visited them and touched them with their antennae, mainly in the anal region. At this, the larvae often released droplets of fluid, which were ingested by the ants. Larvae that were subjected to antennal stroking released honeydew much more frequently than those that were not; their average interval between releases was $1.5 \mathrm{~min}$.

We did not observe feeding or defaecation in adult bugs. The ants were attracted to them far less than to the larvae. They touched them briefly with their antennae and moved on again, sometimes climbing over the adults to reach the larvae. Neither adults nor larvae showed any signs of disturbance when touched by the ants. The ants never behaved aggressively towards the bugs but bit intruding objects, such as forceps, applying defensive fluid from the extruded sting at the tip of the raised gaster. Our group of bugs was deserted at dusk by the Crematogaster workers. At night, the bamboo was frequented by another ant, Camponotus sp., which did not 'milk' the bugs but instead visited tortricid larvae, living at the same nodes, with which they had a trophobiotic relationship (Maschwitz et al., 1986).

In January 1987 we found a further Cloresmus species and the coreid Notobitus affinis (Dallas) which also live in trophobiosis with ants. The genera Notobitus and Cloresmus are closely related. Larvae and adults of both species were collected in Genting Highlands (about $600 \mathrm{~m}$ height), Malaysia. They sucked on fresh bamboo shoots and were visited by the ant Anoplolepis longipes. 


\section{Discussion}

The two newly described formicid/heteropteran associations and the previously reported Hygia cliens/Meranoplus mucronatus association are true trophobioses for these reasons: $(a)$ the bugs excrete large amounts of a sugar-containing fluid that is solicited by the ants; $(b)$ the ants stay with the bugs for long periods, recruit to them and protect them from disturbance and enemies. In the Tropidotylus/M. mucronatus association that we observed, additional protection was given by pavilion shelters. We do not know whether the pavilions were constructed by $M$. mucronatus or taken over from another species of ant; damaged shelters were not repaired by them. Similar pavilions constructed by Crematogaster sp. for the protection of Coptosoma sp. (Plataspidae) were reported by Green (1900); Green's association is undoubtedly also a case of trophobiotic symbiosis. The fact that the release of fluid is triggered by antennal signals from the ants suggests a highly developed symbiosis. Additional support for this view is furnished by the formation of associations by the bugs, their stability and long survivorship and the simultaneous presence of larvae and adults. These factors contribute to a high and long-lasting state of attractiveness of the groups of bugs, to which are recruited a large number of ants which attend and protect them.

Adults of both Cloresmus and Tropidotylus certainly release much less fluid than is excreted by the larvae but they nevertheless receive a high degree of protection through


FIG. 3. Rostra and stylets of phloem-feeding bugs. The long stylets are accommodated in $(a)$ an expansion of the labium (Coptosomoides myrmecophilus), $(b)$ crumena-like invaginations of the head (Tropidotylus fasciolatus), or $(c)$ the elongated but otherwise unmodified labium (Hygia cliens). 
their close association with the latter. It is noteworthy that Cloresmus had trophobiotic relations only with Crematogaster sp., in the daytime, and not with the nocturnal Camponotus sp. that visited trophobiotic tortricid larvae on the same plants.

The frequent release of large amounts of sugary honeydew indicates that all three common species (and presumably also Tropidotylus minister) are phloem-feeders. In the case of Cloresmus, which feeds from superficially situated phloem elements near extrafloral nectaries in the monocotyledonous bamboo, there are no difficulties in reaching the sap. The other bugs, however, have to penetrate the thick bark of the dicotyledonous host tree to reach the phloem elements. In Hygia cliens, the long stylets are housed in the elongated rostrum carried beneath the body. In small larvae this rostrum is longer than the whole body (Fig. 3c). A superficial examination of Tropidotylus, however, reveals only a short rostrum. How, then, can these bugs reach the phloem? China (1931) provides an explanation. In his description of a species of the plataspid genus Coptosomoides, closely related to Tropidotylus, he mentions that the bug is myrmecophilic and speculates that it lives 'in the nests' of a wood-dwelling Camponotus in Sumatra, where it 'would almost certainly be feeding on some fungus'. This is an unjustified inference drawn from a remark by the collector: 'taken with Camponotus'. China discovered that Coptosomoides has very long stylets coiled in the strongly inflated second segment of the rostrum (Fig. 3a), as in Bozius and Aradus. He described a different structure in Tropidotylus (Fig. 3b), where the extremely long stylets are rolled up in a sac-like invagination within the head, reaching far into the body of the bug. This structure strongly resembles the crumena of the coccids. A translucent spot on the head of the adults of our species, together with the raised tylus, shows that the same structure is present. The long stylets are not used for feeding on fungi as China had supposed. Instead, they enable this stem-sucking bug to reach the phloem beneath the thick bark. The other plataspids with long stylets, at least Coptosomoides, are likely to be phloem-feeders living in trophobiosis with ants. In another heteropteran family, Aradidae (bark bugs), extremely long stylets are known to be rolled up within the head (China, 1931). Most aradids are mycophagous (Brauns, 1970) but the European Pinetree Bug, Aradus cinnamomeus, which lives gregariously on the stems of conifers, is reported to be phytophagous. To date, we know of no report of trophobiotic relationships involving phloem-feeding Aradidae. The occurrence of trophobiosis in two bug families, Plataspidae and Coreidae, indicates that this way of life may be more widespread in Heteroptera than has been previously assumed.

Taxonomy (W. R. Dolling)

Coreidae: Colpurini

\section{Hygia (Trichocolpura) cliens sp. nov.}

(Figs 4-6)

Length: $\delta, 9 \cdot 75-9.88 \mathrm{~mm}(n=4) ; \circ, 11 \cdot 13-11.79 \mathrm{~mm}(n=2)$. Width of pronotum: of, 2.84-2.96 mm; o, 3.28-3.42 mm. Length of antenna: os, $4.78-5.30 \mathrm{~mm}$;, $5.68 \mathrm{~mm}$ (only one intact). Length of rostrum: $0,8.36-9.16 \mathrm{~mm} ;$;, $10.64 \mathrm{~mm}$ (only one intact). Length of anterior, intermediate and posterior femora respectively: $0,2 \cdot 24-2 \cdot 48 \mathrm{~mm}$, 2.24-2.36 mm, 2.80-3.20 mm; $9,2.64-2.76 \mathrm{~mm}, 2 \cdot 64-2 \cdot 72 \mathrm{~mm}, 3.28-3.48 \mathrm{~mm}$.

Body oblong. Head (Fig. 4) rather elongate, about 0.85 times as long as pronotum, dorsally convex, tylus and juga prominent, tylus and genae without prominent teeth, bucculae obtusely mucronate. Sides of head in front of eye subparallel, distance from eye to apex of antennifer about 1.5 times length of eye. Preocellar pits deep. Vertex 
much wider than eyes. Postocular tubercles strongly prominent; width across postocular tubercles divided by greatest width across antennifers about $1 \cdot 14$. Antennae about half as long as body. Ratio of lengths of antennal segments I:II:III:IV in $\hat{\sigma}$ about $1 \cdot 00: 1 \cdot 45: 1 \cdot 08: 1 \cdot 38$; in $q$ about $1 \cdot 00: 1 \cdot 50: 1 \cdot 12: 1 \cdot 26$. Rostrum reaching to base of sternum VII. Ratio of lengths of rostral segments I:II:III:IV in both sexes about $1 \cdot 00: 1 \cdot 51: 1 \cdot 50: 1 \cdot 70$.

Pronotum (Fig. 4) with its greatest width about 1.51 times its greatest length, lateral margins somewhat raised anteriorly but anterolateral angles broadly rounded, not prominent. Lateral margins of pronotum weakly concave, anterior and posterior lobes separately convex, separated by a shallow, transverse furrow, posterior lobe with midline broadly and shallowly depressed, anterior lobe not depressed in midline anteriorly but posteriorly with a broad and rather deep median impression. Scutellum triangular, flat, its basal width about 1.03 times its length. Forewing membrane with six to eight, irregularly branched but usually not anastomosing, longitudinal veins. Apex of corium very distinctly embraced by membrane externally. Femora (Fig. 5) each with two rows of teeth ventrally, the teeth of the anterior row smaller and more numerous than those of the posterior row. Tibiae with dorsal sulci wholly obsolete. Lengths of anterior, intermediate and posterior tibiae about $0.88,0.93$ and 1.07 times
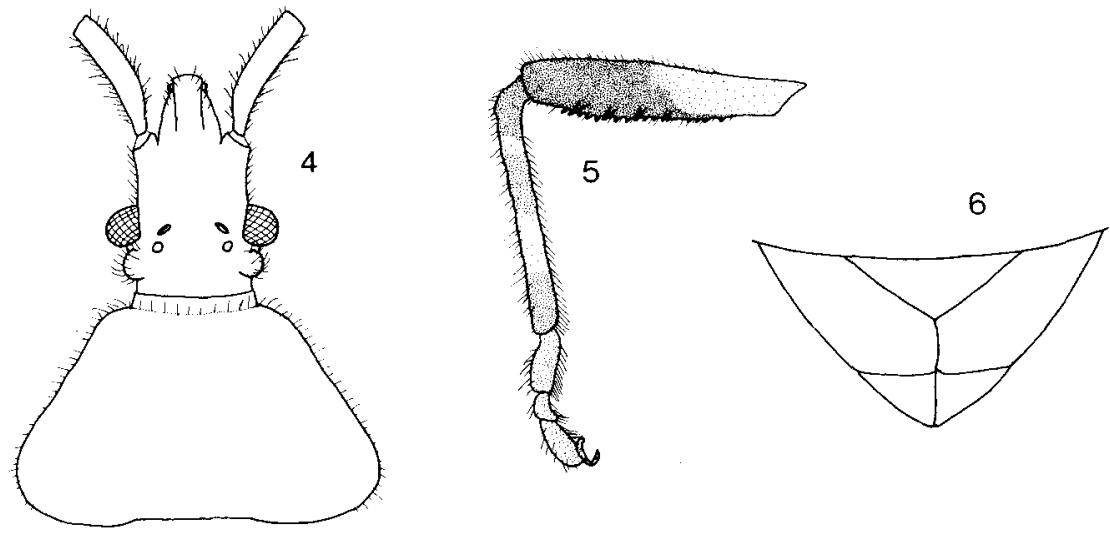

Figs 4-6. Hygia cliens sp. nov. (4) Head, pronotum, antennal segments I, dorsal view. (5) Left intermediate femur, tibia and tarsus, posterior view. (6) Female terminalia, ventral view.

lengths of their respective femora. Abdominal sterna III-VI shallowly sulcate in midline. Male genital capsule with posterior margin entire, neither incised nor produced. Female sternite VII (Fig. 6) with plica obtusely triangular, sides of cleft beyond it overlapping to end of segment, not diverging.

Head, antennae, rostrum, pronotum, scutellum, pleura, thoracic and abdominal sterna, clavus, corium, laterotergites and exposed parts of genital segments all with erect or suberect, bristle-like pubescence; scale-like pubescence lacking; abdominal tergites with sparse, decumbent but bristle-like pubescence. Body surface dull, not shining. Head, pronotum, scutellum, pleura, abdominal sterna, clavus and corium with circular, greyish-white, farinose punctures. Coloration dark brown, clavus and corium somewhat redder than rest of body. Rostrum yellow. Extreme base of antennal segment III yellow. Antennal segment IV creamy white, its basal one-sixth abruptly dark brown. Extreme apex of scutellum and a spot on corium close to middle of its 
distal margin yellow. Forewing membrane cinnamomeous with veins darker brown, basal margin broadly and posterior margin more narrowly piceous. Each laterotergite of segments III to IV with a yellow spot at its posterior external angle and sternites each with a similar spot adjacent to those of laterotergites; posterolateral angles of tergite VII each with a yellow spot. Coxae dark brown. Trochanters yellow. Femora dark brown, basal one-sixth of anterior femur, one-third of intermediate femur and twothirds of posterior femur yellow, the yellow area extending further dorsally than ventrally. Tibiae dark brown, each with a narrow annulus near base and a broader band towards apex yellow. Tarsi yellow with diffuse brown markings.

Nymphs of instars IV and V with femora unarmed and tibiae dorsally sulcate.

HoLOTYPe $\hat{\delta}$, WEST MALAYSIA: Gombak, 21st mile, near Kuala Lumpur, $18 \cdot i \cdot 1973$ (Maschwitz). In British Museum (Natural History), London.

PARATYPES. WEST MALAYSIA: $2 \hat{o}$, one IV instar, one V instar, same data as holotype. One ŝ, Ulu Gombak, i.1986 (Maschwitz); one ô, Perak, Tapan (H.N. Ridley); one 9 , Perak (Doherty, ex coll. Distant); one \%, Bukit Kutu, $3457 \mathrm{ft}[=1054 \mathrm{~m}$ ] (N.C.E. Miller). In British Museum (Natural History), London and J. W. GoetheUniversität, Frankfurt-a-M.

Discussion. Little progress has been made in the classification of the Colpurini ( = Pachycephalinae) since Breddin's (1900) synopsis of the group. The relationships between the various genera and the subgenera of Hygia ( = Colpura, Pachycephalus) are still unclear and the placement of this new species in the subgenus Trichocolpura must be regarded as tentative. Its strongly toothed femora resemble those of the genus Homalocolpura but there are many points of difference: in Homalocolpura the bucculae are rounded, not angulate; the body surface is shiny, not dull; the head and pronotum are characteristically short, not elongate; and the sides of the cleft in the seventh abdominal sternite of the female diverge beyond the plica instead of overlapping to the end of the segment as in the new species. Most of the characters of cliens are consistent with its membership of the large and diverse genus Hygia. The lack of reticulate venation and the rounded, not prominent, anterolateral angles of the pronotum exclude it from Hygia s. str. and the non-prominent genae exclude it from Colpura and Eucolpura. Of the remaining subgenera, only Trichocolpura has erect, hair-like pubescence instead of decumbent or semidecumbent, scale-like pubescence. Sphinctocolpura, which has denticulate femora, differs not only in the pubescence but also in the characteristic colour pattern of the femora, which are yellow with rows of brown spots, whereas the other subgenera have the femora yellow basally and either uniformly brown or mottled brown and yellow apically. Of the other subgenera with squamiform pubescence, Stenocolpura has the plica of the female seventh sternum long and acute, not short and obtuse; Caracolpura has the head flat, not convex, dorsally; and in Microcolpura the transverse furrow of the pronotum is obsolete, not well marked. For these reasons cliens is placed in the subgenus Trichocolpura despite the considerable differences between it and the only other species of the subgenus, $H$. (T.) schultheissi Breddin. The most obvious points in which cliens differs are the toothed femora and the lack of pale bands on the pronotum and corium; additionally, the male genital capsule has the posterior margin entire, whereas it has a deep median incision in schultheissi, the antennae are shorter and the proportions of their segments differ and the femora apically are uniform brown, not mottled. Obvious similarities are the pubescence, the shape of the head and pronotum, the form of the female seventh sternum and the fact that the apex of the corium is broadly embraced by the membrane. 
Coreidae: Cloresmini

\section{Cloresmus sp.}

A species of Cloresmus was observed in association with ants on bamboo. Probably all species of this genus, and of the related Notobitus, are associated with bamboos and perhaps other tall grasses. Our species is not conspecific with any of the named material in the British Museum (Natural History). We have not yet examined authentically determined material of Cloresmus signoreti Stal, described from Java, and believe it is possible that this is the species before us.

\section{Plataspidae}

\section{Tropidotylus servus sp. nov.}

(Figs $7-10,12,14)$

Length: $0,5 \cdot 9-6 \cdot 3 \mathrm{~mm}(n=2) ; 9,6 \cdot 8-7 \cdot 0 \mathrm{~mm}(n=5)$. Width of head including eyes: o, $2.1 \mathrm{~mm}$;,$+ 2.1 \mathrm{~mm}$. Greatest width of pronotum: $0,4.3 \mathrm{~mm}$; $9,4.9 \mathrm{~mm}$. Greatest width of scutellum: $\delta, 5.1 \mathrm{~mm}, 9,5.8 \mathrm{~mm}$. Antennae (Fig. 12) with four segments; lengths of segments I-IV: o, 0.46, 0.72, 0.71, 0.83 mm; $, 0.48,0.79,0.79,0.89 \mathrm{~mm}$. Body shape (Fig. 7) and form of tylus (Fig. 8) typical for the genus. Auricle of metathoracic scent-gland peritreme (Fig. 9) triangularly expanded at apex. Paramere of male broad, with apical tooth short and broad (Fig. 10). Aedeagus (Fig. 14) with three pairs of sclerotized appendages.
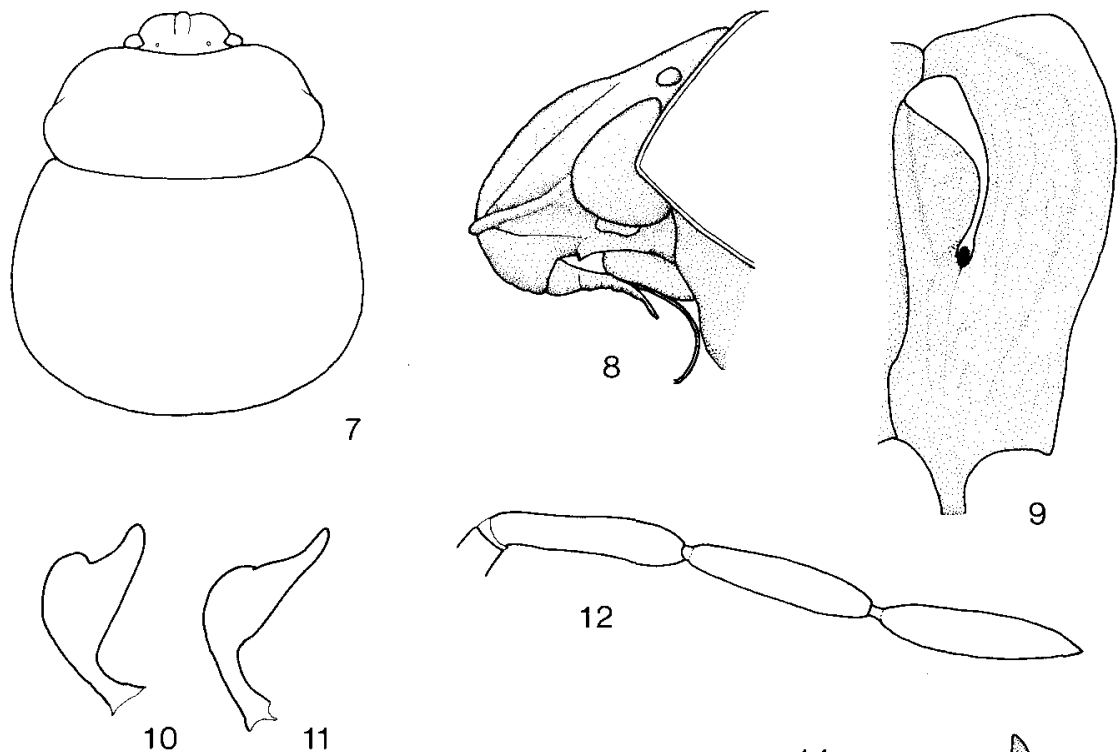

11

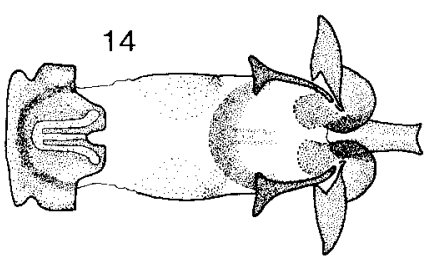

FIGs 7-14. Tropidotylus species. (7-10) T. servus sp. nov.: 7, dorsal view, outline; 8, head, left lateral view; 9, left metapleuron; 10 , paramere. (11) $T$. minister sp. nov., paramere. (12) $T$. servus, antenna. (13) T. fasciolatus Stål, antenna. (14) T. servus, inflated aedeagus, ventral view. 
Upper and lower surfaces, except for underside of thorax, glossy. Upper surface somewhat sparsely punctured, the punctures well separated. Head with conspicuous, short pubescence. Pronotum and scutellum with inconspicuous, very short, sparse pubescence arising from the punctures, appearing almost glabrous except in profile. General coloration of upper surface creamy yellow, mainly obliterated by large, confluent, brown spots associated with the punctures but everywhere with consicuous, strongly contrasting, irregularly shaped, impunctate patches of the ground colour remaining unobscured so that, to the unaided eye, insect appears brown with pale yellow spots. Antennae with segment I yellow, II pale brown basally and dark brown apically, III and IV dark brown. Rostrum and legs yellow. Ventral surface of head and prothorax sordid yellow; mesopleura and metapleura dark brown; mesosterna and metasterna black; metapleural scent-gland auricle orange-yellow; disc of abdomen piceous, sterna laterally castaneous, III-VII each with a large, creamy yellow spot on each side adjacent to lateral margin and enclosing the brown-ringed spiracle and a brown spot in which the trichobothria are situated.

HoLotyPE $\precsim$ $\precsim$, WEST MALAYSIA: Ulu Gombak, January 1986 (Maschwitz). In British Museum (Natural History), London.

ParatyPes: $1 \delta, 5 \%$, data as holotype. In J.W. Goethe-Universität, Frankfurt-a-M and British Museum (Natural History), London.

Discussion. See under T. minister (below).

\section{Tropidotylus minister sp. nov.}

(Fig. 11)

Length: $ð, 5.6-5.7 \mathrm{~mm}$; $q$ unknown. Width of head including eyes $1.8 \mathrm{~mm}$. Greatest width of pronotum $4.0 \mathrm{~mm}$. Greatest width of scutellum $4.7 \mathrm{~mm}$. Antennae with four segments; lengths of segments I-IV: $0.42,0.64,0.62,0.69 \mathrm{~mm}$. Paramere (Fig. 11) moderately broad, its apical tooth longer and more slender than that of $T$. servus. Aedeagus and scent-gland peritreme as in servus. Upper surface subshining. Head sparsely, pronotum and scutellum densely and somewhat rugosely punctured. Whole upper surface covered with conspicuous, short, erect, colourless pubescence arising from the punctures. General coloration of upper surface orange-brown, very largely obscured by confluent brown spots associated with the punctures, ground colour only apparent on head, anterior one-third of pronotum and midline and perimeter of scutellum. Contrast between pale and dark areas not very great, insect appearing dull brown to the unaided eye. Antennae with segments I and II yellow, II infuscate apically, III and IV fuscous. Rostrum and legs yellow. Underside of head glossy yellow, of thorax matt yellow-brown with mesosterna and metasterna black; metapleural scent-gland auricle orange-yellow; underside of abdomen glossy orangeyellow with fine, brown puncturation laterally, disc brown.

HolotyPe $\curvearrowright$, WEST MALAYSIA: Ulu Gombak, January 1986 (Maschwitz). In British Museum (Natural History), London.

PARATYPE: $1 \hat{\sigma}$, data as holotype. In J.W. Goethe-Universität, Frankfurt-a-M.

Discussion. These two species of Plataspidae belong to the Coptosoma group as defined by Jessop (1983: 33). The characteristic structure of the tylus indicates a close relationship with the genus Tropidotylus. Yang (1936:478-479) described a new genus, Chinacoris, for a species from Indo-China with the tylus similarly raised but his genus 
differs from Tropidotylus in the more strongly flared anterolateral angles of the pronotum and the bold colour pattern: black, with two large, yellow patches on the pronotum plus two small and two large yellow patches on the scutellum. Both the new species differ from Chinacoris, and from the previously described members of the genus, in having only four antennal segments. Apart from the number of antennal segments, $T$. servus is almost identical in size, shape and colour pattern with $T$. fasciolatus Stal. The second antennal segment of fasciolatus is by far the shortest (Fig. 13). The nymphs of Plataspidae, like most Pentatomoidea, have four-segmented antennae and the second segment divides at the final moult to give rise to the fivesegmented adult condition. Clearly, this division does not occur in the two new species of Tropidotylus.

\section{Acknowledgements}

The fieldwork in this study was supported by the Deutsche Forschungsgemeinschaft.

\section{References}

Brauns, A., 1970. Taschenbuch der Waldinsekten. Vol. 1. Stuttgart: Fischer.

Breddin, G., 1900. Materiae ad cognitionem subfamiliae Pachycephalini (Lybantini olim) ex Hemipteris-Heteropteris, Fam. Coreidae. Revue d'Entomologie 19, 194- 217.

China, W. E., 1931. Morphological parallelism in the structure of the labium in the hemipterous Coptosomoides gen. nov., and Bozius, Dist. (Fam. Plataspidae) in connection with mycetophagous habits. Annals and Magazine of Natural History (10) 7, 281-286.

GREEN, E., 1900. Note on the attractive properties of certain larval Hemiptera. Entomologist's Monthly Magazine 11 (2), 185.

JESSOP, L., 1983. A review of the genera of Plataspidae (Hemiptera) related to Libyaspis, with a revision of Cantharodes. Journal of Natural History 17, 31-62.

Maschwitz, U. and Klinger, R., 1974. Trophobiontische Beziehungen zwischen Wanzen und Ameisen. Insectes Sociaux 21, 163-166.

Maschwitz, U., Dumpert, K. and Tuck, K. R., 1986. Ants feeding on anal exudate from tortricid larvae: a new type of trophobiosis. Journal of Natural History 20, 1041-1050.

YANG, W. I., 1936. Descriptions of a new family and three new genera of hemipterous insects. Annals and Magazine of Natural History (10) 16, 476-482. 